\title{
Geoconservação no geomorfossítio Complexo Mini Cânion do Rio Poti, Juazeiro do Piauí, Piauí, Brasil
}

\section{Geoconservation in the geomorphosite Complexo Mini Cânion do Rio Poti, Juazeiro do Piauí, Piauí, Brazil}

\author{
Helena Vanessa Maria da Silva ${ }^{* 1} \bowtie(\mathbb{0}$, Claudia Maria Sabóia de Aquino $₫(\mathbb{1}$, \\ Renê Pedro de Aquino $₫$ (D) \\ ${ }^{1}$ Departamento de Geografia, Universidade Federal do Piauí, Teresina, Piauí, Brasil \\ ${ }^{2}$ Departamento de Geografia, Universidade Estadual do Piauí, Teresina, Piauí, Brasil \\ E-mail: cmsaboia@gmail.com (CMSA); rene.uespi@hotmail.com (RPA) \\ *E-mail para correspondência: helenavessa18@gmail.com
}

Recebido (Received): 26/05/2020 Aceito (Accepted): 18/10/2020

Resumo: O geomorfossítio Complexo Mini Cânion do Rio Poti fica localizado no município de Juazeiro do Piauí, Centro-Norte do Estado. Caracterizado como um vale encaixado, com drenagem que tende a se profundar à medida que escava o substrato rochoso, o trabalho da erosão diferencial favorece a formação de patamares no leito do rio, os agentes erosivos desintegram o arenito de acordo com o seu grau de resistência o que possibilita dar forma ao vale, originando um cânion de grande beleza cênica. Com valores científico, didático, ecológico, turístico, cultural, estético e econômico elevado as singularidades geológicas e geomorfológicas do local são variadas. Diante desse contexto, este trabalho tem como objetivo avaliar e propor estratégias de geoconservação para o referido geomorfossítio, para tanto foi realizado o inventário, a avaliação quantitativa e propostas medidas de valorização e divulgação. Para o desenvolvimento da pesquisa os procedimentos operacionais compreenderam análise bibliográfica, trabalhos de gabinete e realização de trabalho de campo orientado por fichas com base em Oliveira (2015) e Pereira (2006). Constatou-se que o referido geomorfossítio é um espaço passível de utilização em atividades científicas, educativas e geoturísticas, tanto por suas aptidões como pelo baixo risco de degradação. As medidas de valorização e divulgação propostas foram: confecção de um painel interpretativo e confecção de souvenires. As propostas expõem o caráter aplicado dos estudos em geoconservação ao integrar conceitos relativos às temáticas da interpretação ambiental, educação ambiental e geocomunicação.

Palavras-chaves: Geodiversidade; Patrimônio Geomorfológico; Geoturismo.

Abstract: The Geomorphosite Complexo Mini Cânion do Rio Poti is located in the municipality of Juazeiro do Piauí, in the Center-North of the State. Characterized as an embedded valley, with drainage that tends to deepen as it excavates the rocky substrate, the work of differential erosion favors the formation of plateaus in the riverbed, the erosive agents disintegrate the sandstone according to its degree of resistance which makes it possible to shape the valley, creating a canyon of great scenic beauty. With high scientific, didactic, ecological, touristic, cultural, aesthetic and economic values, the geological and geomorphological singularities of the place are varied. In this context, this work aims to evaluate and propose geoconservation strategies for the aforementioned geomorphosite, for this purpose the inventory, quantitative assessment and proposed valuation and dissemination measures were carried out. For the development of the research, the operational procedures included bibliographic analysis, office work and field work guided by worksheets based on Oliveira (2015) and Pereira (2006). It was found that the aforementioned geomorphosite is a space that can be used in scientific, educational and geotouristic activities, both for its aptitudes and for the low risk of degradation. The proposed valuation and dissemination measures were: making an interpretive panel and making souvenirs. The proposals expose the applied character of studies in geoconservation by integrating concepts related to the themes of environmental interpretation, environmental education and geocommunication.

Keywords: Geodiversit;: Geomorphological Heritage; Geotourism. 


\section{Introdução}

O geomorfossítio Complexo Mini Cânion do Rio Poti fica localizado no município de Juazeiro do Piauí, Centro-Norte do Estado. Caracterizado como um vale encaixado, com drenagem que tende a se profundar à medida que escava o substrato rochoso, o trabalho da erosão diferencial favorece a formação de patamares no leito do rio, os agentes erosivos desintegram o arenito de acordo com o seu grau de resistência o que possibilita dar forma ao vale, originando um cânion de grande beleza cênica.

O local configura um importante espaço passível de utilização em atividades científicas, educativas e geoturísticas. Seus potenciais do ponto de vista científico/didático, turístico e cultural são expressivos, de caráter cênico excepcional suas geoformas e a singularidade visual dos elementos geomorfológicos aliado a aspectos culturais físicos e imateriais de elevado valor possibilitam explicar parte da história geológica/evolutiva do Estado, por meio do entendimento da origem e constante modificação do relevo da área.

Seu uso em atividades de educação ambiental, no desenvolvimento turístico e no enriquecimento do conhecimento sobre as características geológicas, geomorfológicas e arqueológicas são fundamentais.

Diante desse contexto, o presente trabalho teve como objetivo avaliar e propor estratégias de geoconservação para o referido geomorfossítio, para tanto foi realizado o inventário, a avaliação quantitativa e propostas de valorização e divulgação, segundo Oliveira (2015) e Pereira (2006) buscando potencializar os valores, sobretudo no viés turístico com a exploração didático-científica e cultural do referido geomorfossítio.

Pontuando particularidades diversas as singularidades geológica/geomorfológica e cultural do geomorfossítio Complexo Mini Cânion do Rio Poti são excepcionais. A exploração deste potencial de modo sustentável poderá proporcionar a geração de renda e consequentemente melhorias da qualidade de vida das populações residentes na área.

\section{Materiais e métodos}

A metodologia utilizada parte da realização de estratégias de geoconservação, definida por Rodrigues e Bento (2018) pelas etapas de inventariação; quantificação; enquadramento legal; conservação; valorização, divulgação e monitoramento. Mediante os objetivos propostos para o trabalho, foram suprimidas as etapas de enquadramento legal; conservação e monitoramento.

Salienta-se que o estudo está inserido num esforço maior quanto à pesquisa e a avaliação do patrimônio geológico/geomorfológico no município de Juazeiro do Piauí. Pesquisa desenvolvida no âmbito do trabalho de dissertação intitulado "Geodiversidade e Geopatrimônio dos municípios de Juazeiro do Piauí, Novo Santo Antônio, São João da Serra e Sigefredo Pacheco, Piaú'".

Para a efetivação da pesquisa, foi realizado inicialmente um levantamento bibliográfico sobre os aspectos ambientais do local, dando ênfase às abordagens sobre a geodiversidade e geoconservação. Além disso, foram gerados materiais cartográficos básicos, tendo como base dados de geologia, geomorfologia, hidrografia e solos.

Para o inventário (identificação, avaliação qualitativa e a caracterização) do geomorfossítio utilizou-se a ficha descritiva de Oliveira (2015), a qual adequa-se a áreas de qualquer dimensão. Empregada no território brasileiro, municípios de Coromandel e Vazante (Minas Gerais) é voltada especificamente para o patrimônio geomorfológico.

Na avaliação quantitativa do geomorfossítio foi adotada a metodologia de Pereira (2006) uma grande referência para pesquisas nesse âmbito, utilizada pela comunidade científica, tanto nacional como internacional. Para a avaliação numérica Pereira (2006), propõe uma ficha a qual deve ser preenchida após a caracterização dos locais. A mesma apresenta critérios, parâmetros e notas que definem valores (científico, adicional, geomorfológico, de uso de preservação e de gestão). Dessa forma, o método traz um contributo prático, sendo uma ferramenta para ampliar as justificativas quanto à conservação do patrimônio geomorfológico.

$\mathrm{Na}$ valorização e divulgação foram gerados produtos gráficos com base nas informações adquiridas. Dessa forma, se propõe um painel interpretativo e confecção de souvenires como estratégias de valorização e divulgação do patrimônio geológico/geomorfológico do local. 


\section{Geoconservação: princípios e conceitos}

As medidas relacionadas à conservação dos elementos naturais abióticos (geodiversidade) apresentam um histórico antigo. De acordo com Mansur (2018) o primeiro caso de proteção legal atribuída a um sítio natural, de natureza abiótica, ocorreu em 1868, na Alemanha, indicando a proteção da caverna de Baumann, onde o objeto de ordem de conservação a caverna de Baumann é um dos geossítios de Harz Geopark. Outros importantes sítios localizados em Edimburgo, Escócia, também fazem parte da história da geoconservação, desde o século XIX.

Internacionalmente outro importante marco para a geoconservação foi à criação, em 1872, do Parque Nacional de Yellowstone, Estados Unidos, em grande parte por sua beleza cênica e maravilhas geológicas (GRAY, 2004).

A partir desse momento, medidas em prol da conservação do patrimônio geológico passaram a ser tomadas em nível mundial. Wimbledon et al. (1999) citado por Pereira (2010) elenca algumas das principais ações, como a criação da ProGEO (European Association for the Conservation of the Geological Heritage) em 1988, sob o auspício da "European Working Group for Earth Science Conservation".

Outros momentos relevantes para a geoconservação são compreendidos pela instituição do GILGES (Global Indicative List of Geological Sites) em 1989, o qual constituia em um inventário mundial de sítios geológicos. Além da realização do $2^{\circ}$ Simpósio Internacional sobre a Conservação do Patrimônio Geológico, na cidade de Roma, no ano de 1996, que também foi um marco importante, onde [...] foi criado o Projeto GEOSITES e estabelecido o grupo de trabalho: GGWG - Global Geosites Working Group, da União Internacional das Ciências Geológicas - IUGS (PEREIRA, 2010; MEIRA, MORAIS, 2016).

Sobre o tema geoconservação ainda podem ser destacados dois livros que contribuem grandemente para o entendimento conceitual de sua aplicação e alcance: "The History of Geoconservation" editado por Burek e Prosser (2008) e "Geoconservación” de Carcavilla (2012) (NASCIMENTO; MANSUR; MOREIRA, 2015).

Outro grande avanço foi o lançamento do Programa Geoparks pela UNESCO, em 1999, que visa distinguir regiões que abrigam um patrimônio geológico relevante e nas quais esteja em prática uma estratégia de desenvolvimento sustentado baseado na geologia e em outros valores naturais e humanos (MANSUR, 2018).

Em âmbito nacional sua expansão ocorreu, principalmente, a partir de 1997 com a criação da Comissão Brasileira dos Sítios Geológicos e Paleobiológicos (SIGEP), intensificando-se no início dos anos 2000, com inúmeros eventos, especialmente o XLII Congresso Brasileiro de Geologia ocorrido em 2004, e trabalhos desenvolvidos no país referentes a esta temática (RUCHKYS, 2007; PEREIRA, 2010, BAPTISTA et al. 2018).

Diante do contexto delineado o destaque é para a publicação de Nascimento, Ruchkys e Mantesso-Neto (2008), obra intitulada "Geodiversidade, geoconservação e geoturismo: trinômio importante para a proteção do patrimônio geológico", um livro com abordagem mais ampla, lançado pela Sociedade Brasileira de Geologia.

Desde então, a geodiversidade tem sido alvo de várias práticas de geoconservação, que a alcançaram de maneira indireta há muito tempo. No entanto, na realidade ainda são poucas as iniciativas legais relacionadas ao patrimônio geológico/geomorfológico no Brasil, porém pode-se observar que ao longo do século XX diversos instrumentos relacionados à proteção do patrimônio natural foram implementados em várias escalas.

O Brasil têm direcionado esforços, embora ainda insuficientes para atingir tal geoconservação. No país, por exemplo, ainda não há leis específicas sobre o tema, apenas a Constituição Federal, em seu artigo 216 versa sobre o patrimônio cultural material e imaterial brasileiro, e indiretamente trata da geodiversidade e da necessidade de sua conservação (SILVA, 2017).

Silva (2017) ainda enfatiza que a origem do termo geoconservação remete a Europa, em 1991, diante a elaboração da Declaração Internacional dos Direitos à Memória Terra, também conhecida como Carta de Digne, resultante do $1^{\circ}$ Simpósio Internacional sobre a Proteção do Patrimônio Geológico, ocorrido em Digne-les-Bains (França).

A partir desse contexto, diversos países começaram a desenvolver trabalhos de inventário do seu geopatrimônio com vistas à geoconservação e uso turístico dos mesmos (LORENCI, 2013). As primeiras preocupações com a geoconservação resultaram dos primeiros movimentos conservacionistas mundiais, a exemplo da Conferência de Estocolmo de 1972, tendo ganhado força a partir da década de 1990 (NASCIMENTO; RUCHKYS; MANTESSO-NETO, 2008; SILVA, 2017). 
A geoconservação se constitui assim como um novo paradigma da conservação do meio natural. Configura-se como uma nova corrente de pensamento que propõe uma abordagem das temáticas relacionadas com a proteção e conservação da natureza (PEREIRA; BRILHA; MARTINEZ, 2008). Devido o termo ser recente ainda não há consenso entre os especialistas quanto a sua definição (BRILHA, 2005). "As diversas definições da literatura especializada sobre geoconservação não são antagônicas, e muitas se completam" (MANSUR, 2018, p. 31).

Um dos primeiros autores a propor uma definição formal pra o termo "Geoconservação" foi Chris Sharples. O referido autor define geoconservação como forma de preservar a geodiversidade relacionada aos importantes processos e feições geológicas, geomorfológicas e de solos, garantindo a manutenção da história de sua evolução em termos de velocidade e magnitude (SHARPLES, 2002). Segundo o mesmo, a geoconservação tem como objetivo a preservação da diversidade natural (ou geodiversidade) de significativos aspectos e processos geológicos (substrato), geomorfológicos (formas de passagem) e de solo, mantendo a evolução natural (velocidade e intensidade) desses aspectos e processos.

Para Stürm (1996), citado por Lima (2008 p. 05), a geoconservação deve “[...] promover, suportar e coordenar esforços em prol do uso sustentável da geodiversidade, além de salvaguardar o patrimônio geológico". Já de acordo com o conceito apresentado por Nascimento, Ruchkys e Mantesso-Neto, (2008, p. 21) "[...] a geoconservação refere-se à conservação do patrimônio geológico e, consequentemente da Geodiversidade".

Carcavilla Urquí, López-Martínez e Durán (2007) por sua vez a definiram como um conjunto de técnicas e medidas destinadas a assegurar sua conservação com base na análise de seus valores intrísecos, vulnerabilidade, e risco de degradação. Já Ruchkys (2007) afirma que a geoconservação da natureza representa uma responsabilidade internacional, uma vez que as áreas de interesse geológico e seus atributos não "respeitam" os limites impostos pelas fronteiras político-administrativas e, muitas vezes, as ultrapassam.

Segundo Cumbe (2007, p. 43 citado por MEIRA, SANTOS, 2016, p. 04) a geoconservação consiste assim, em "atividades que têm com finalidade a conservação e gestão do patrimônio geológico e dos processos naturais a ele associados". "Compreende as intenções e atividades desenvolvidas para conservar e proteger feições e processos geológicos para benefício das futuras gerações" (WORTON, 2008, citado por MANSUR, 2018, p.32).

Brilha e Carvalho (2010) a entendem como o conjunto das iniciativas que vão desde a inventariação e caracterização do património geológico, passando pela sua conservação e gestão, de modo a assegurar um uso adequado dos geossítios, quer ele seja de índole científica, educativa, turística ou outra.

Já Pereira (2010) considera que a geoconservação possui como base a conservação dos elementos naturais, a promoção da identidade do território e o uso racional dos elementos que compõem a geodiversidade por meio do geoturismo, com vistas a perpetuar esses elementos e fazer com que moradores e visitantes se sintam sensibilizados quanto a seu valor científico e educativo.

Dessa forma, pode ser definida conforme Lorenci (2013, p. 67) como

[...] uma atividade voltada para a conservação do Patrimônio Geológico de uma região, visando a sustentabilidade dos geossítios que expressam valor cultural, histórico, científico, educativo, turístico, econômico e que quando inventariados, identificados, classificados, tem como principal objetivo a conservação e a divulgação deste patrimônio representativo de um território onde o desenvolvimento deve ser sustentável.

Quantos aos objetivos da geoconservação Brilha (2005) destaca os seguintes: utilizar e gerir de forma sustentável toda a geodiversidade, e em sentido restrito, apenas a parcela da geodiversidade que apresente valor superlativo.

Nesse sentido, mais que proteger o patrimônio abiótico, a geoconservação propõe-se a reconhecer a diversidade dos processos geológicos, geomorfológicos e pedológicos, e outros, em busca de minimizar os impactos negativos causados pelo ser humano, de forma a promover um consumo sustentável dos recursos naturais.

\section{Resultados e discussões}

O geomorfossítio Complexo Mini Cânion do Rio Poti está localizado no município de Juazeiro do Piauí, que pertencente à Região Geográfica Intermediária de Teresina, mais precisamente na parte Centro-Norte Piauiense. Tem como limite territorial ao norte os municípios de Sigefredo Pacheco e Milton Brandão, ao 
sul, Castelo do Piauí e Buriti dos Montes, a leste Buriti dos Montes, e a oeste Castelo do Piauí e Sigefredo Pacheco (AGUIAR \& GOMES, 2004) (Figura 1).

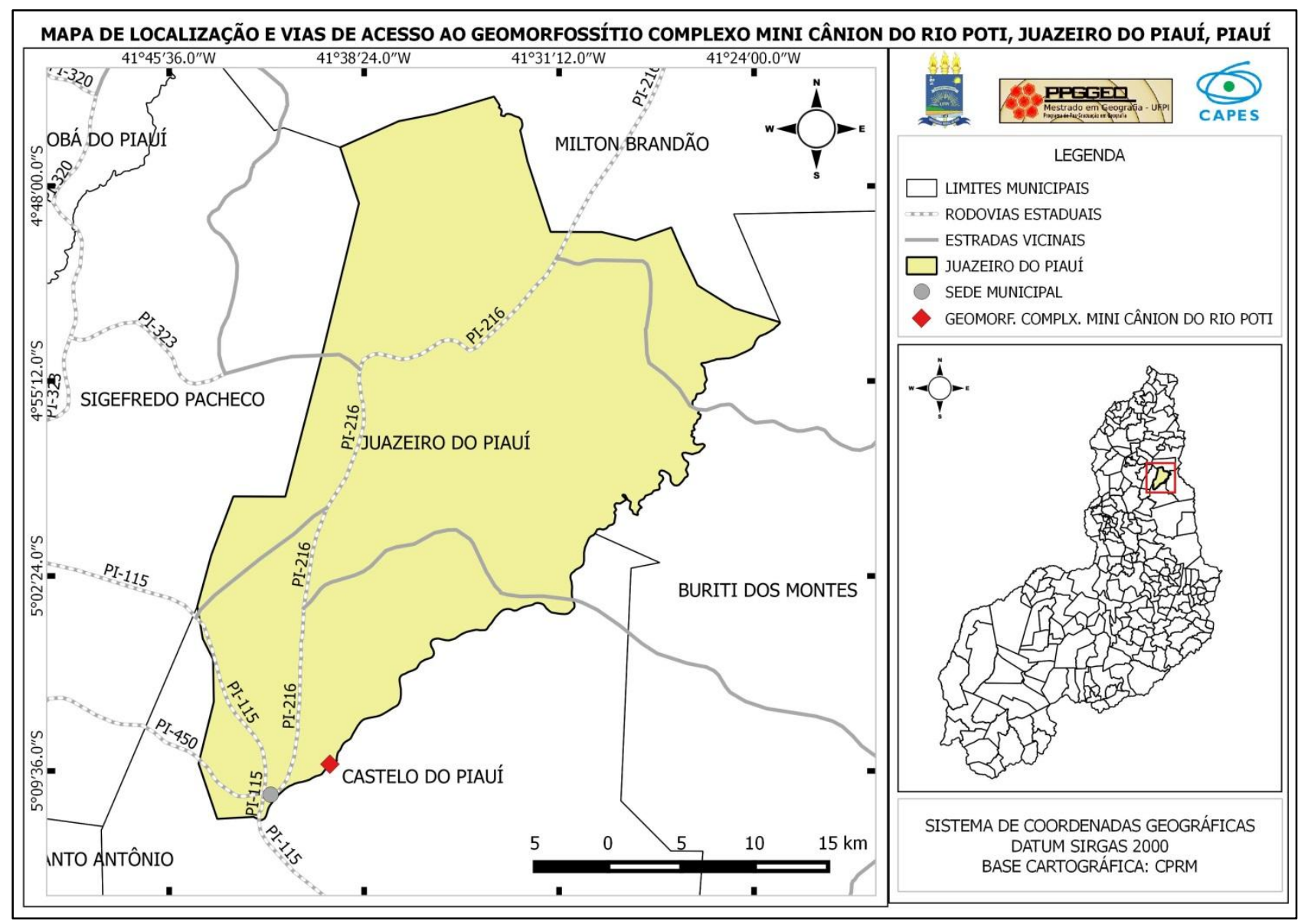

Figura 1: Localização do Geomorfossítio Complexo Mini Cânion do Rio Poti, Juazeiro do Piauí, Estado do Piauí.

A seguir será discutido como se deu o inventário e avaliação quantitativa do geomorfossítio Complexo Mini Cânion do Rio Poti. Etapas iniciais para fins de geoconservação a inventariação (identificação, avaliação qualitativa e a caracterização) do geomorfossítio Complexo Mini Cânion do Rio Poti baseou-se na metodologia de Oliveira (2015), a qual adequa-se a áreas de qualquer dimensão. Já a quantificação constitui a segunda etapa de uma estratégia de geoconservação e consiste na atribuição de valores numéricos a locais de interesse geomorfológico ou outros, funcionando como um complemento da avaliação qualitativa já realizada (PEREIRA, 2006).

\subsection{Inventário e avaliação quantitativa do geomorfossítio Complexo Mini Cânion do Rio Poti}

Local do tipo isolado, área privada, localidade Mansinho, o geomorfossítio Complexo Mini Cânion do Rio Poti (Médio Curso da Bacia Hidrográfica do rio Poti) localiza-se nas coordenadas $05^{\circ} 09^{\prime} 21.5^{\prime}$ "de latitude sul e $041^{\circ} 39^{\prime} 40.4^{\prime \prime}$ de longitude oeste.

Quanto o substrato rochoso o referido geomorfossítio está assentado sobre rochas da Formação Cabeças, Grupo Canindé, que reúne arenito, conglomerado e siltito (Figura 2). Oriundos da deposição de um sistema nerítico plataformal, em regime de maior energia deposicional, datada do Paleozóico e Período Devoniano Médio (Neofrasniano/Eoframeniano), essa formação é dominantemente arenosa, seus arenitos possui aspecto maciço devido à sua estratificação espessa, comumente cruzada bem desenvolvida. "Esta formação geralmente surge em ambiente fluvial, estuário e marinho raso" (LIMA; BRANDÃO, 2010, p. 20). 


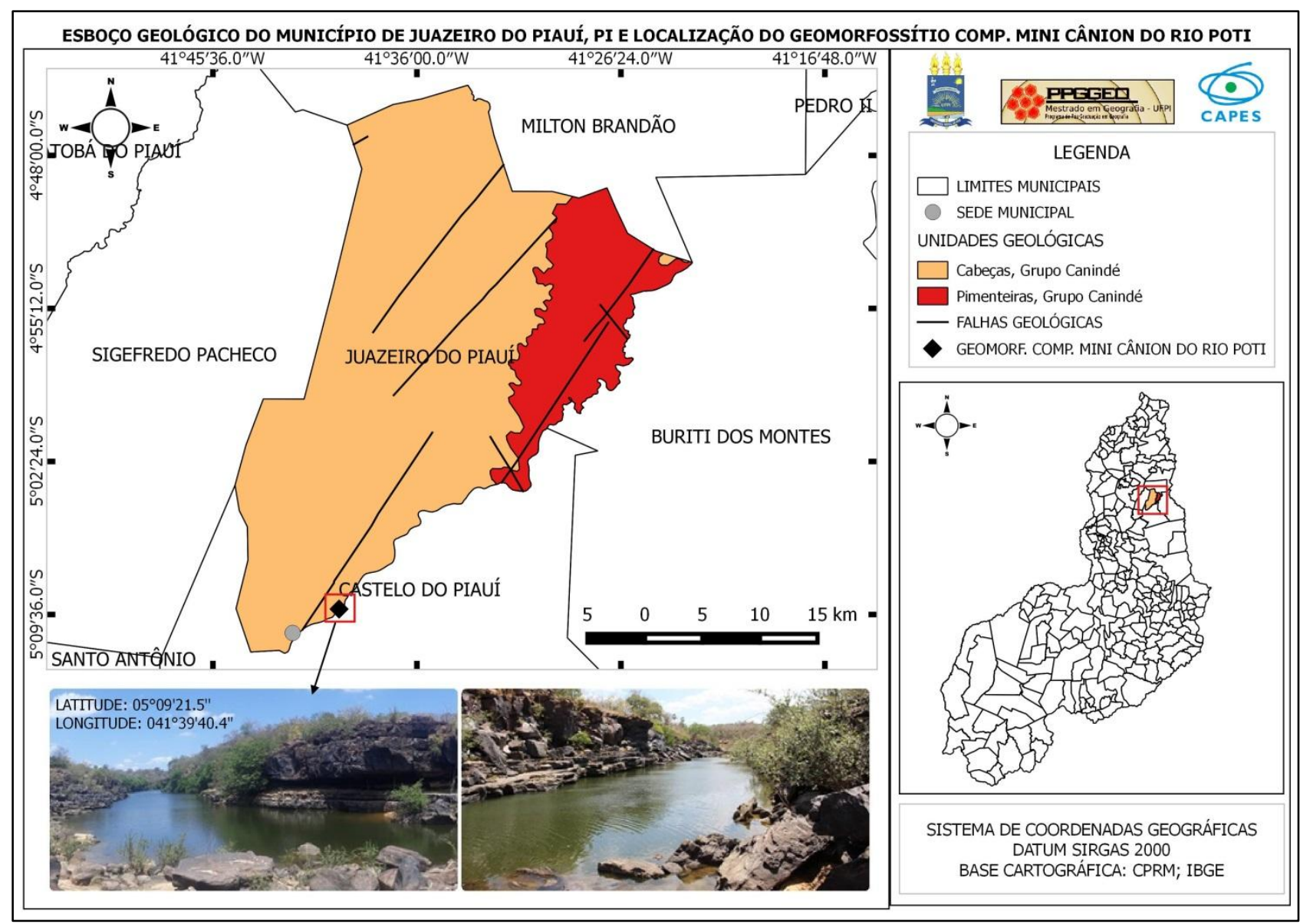

Figura 2: Mapa do esboço geológico do município de Juazeiro do Piauí e localização do geomorfossítio Complexo Mini Cânion do Rio Poti.

De acordo com a compartimentação geomorfológica do Piaú, proposta por Lima (1987, p. 21) o geomorfossítio fica localizado no Planalto Oriental da Bacia do Maranhão Piauí, que

[...] localiza-se na bacia sedimentar do Maranhão-Piauí, no contato leste com o Ceará. Apresenta uma área aproximadamente de $43.000 \mathrm{~km}^{2}$, em torno de $17,2 \%$ da área total do Piauí e 20,6\% da porção piauiense da bacia sedimentar. Topograficamente, essa área [...] forma uma grande linha de cuesta, cujo o "front" está voltado para as depressões sertanejas cearenses e o reverso para o Piauí. [...].

Geomorfologicamente esse compartimento é representado pelos reversos de cuestas conservadas em estruturas monoclinais, depressões monoclinais e vales encaixados, destacando o canyon ou boqueirão do Poti, além das formas de relevo, com a do tipo ruiniforme, feições geomorfológicas que representa caráter residual que se forma a partir do desgaste provocado pela erosão plúvio/eólica, segundo os planos de diáclasses (LIMA, 1987). Podem ser encontradas feições geomorfológicas que compreendem desde superfície aplainada com presença de áreas deprimidas, formando lagoas temporárias, até relevo plano com partes suavemente onduladas com altitudes variando de 150 a 300 metros (SANTOS, 2018, SILVA; AQUINO, 2019).

No município de Juazeiro do Piauí são identificadas as seguintes unidades geomorfológicas: 1 Patamares do Rio Parnaíba e 2 - Planalto da Ibiapaba. O geomorfossítio Complexo Mini Cânion do Rio Poti fica localizado no Dominío das Superfícies Aplainadas da Bacia do Rio Parnaíba ou Patamares do Rio Parnaíba, que "consiste em uma vasta superfície arrasada por processos de erosão generalizados do relevo em diferentes níveis altimétricos, invariavelmente em cotas baixas, entre 50 e 300 m" (FERREIRA; DANTAS, 2010, p. 49) (Figura 3).

Quanto à hipsometria, conforme o Banco de Dados Geomorfométricos do Brasil (TOPODATA) o que se pode observar são áreas com o predomínio de classes de valores que superam os $150 \mathrm{~m}$ de altitude (Figura 4). O geomorfossítio em questão possuí 124 metros de altitude. 


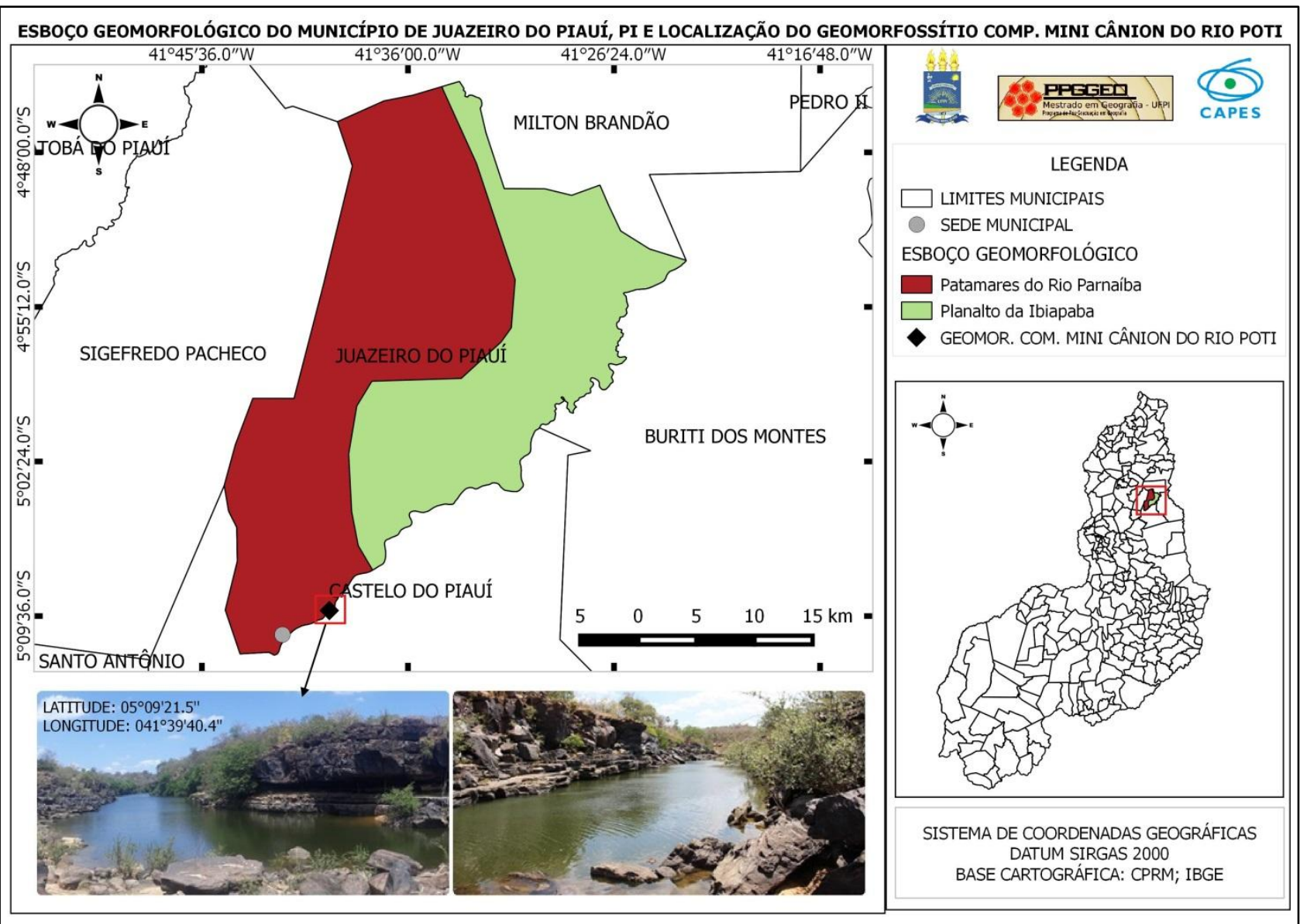

Figura 3: Mapa do esboço geomorfológico do município de Juazeiro do Piauí e localização do geomorfossítio Complexo Mini Cânion do Rio Poti.

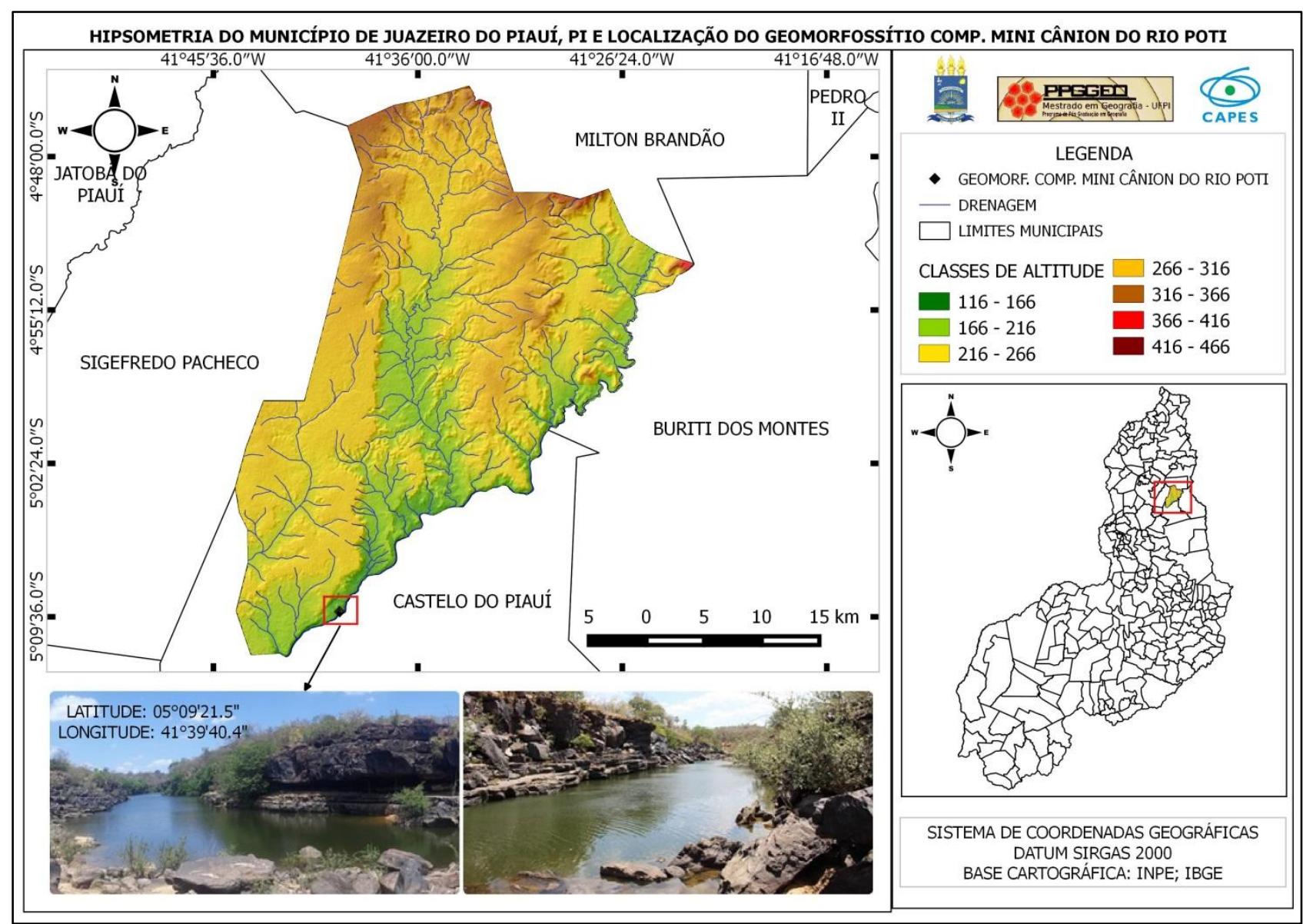

Figura 4: Mapa hipsométrico do município de Juazeiro do Piauí e localização do geomorfossítio Complexo Mini Cânion do Rio Poti. 
Caracterizado como um vale encaixado, com drenagem que tende a se profundar à medida que escava o substrato rochoso, o trabalho da erosão diferencial favorece a formação de patamares no leito do rio, os agentes erosivos desintegram o arenito de acordo com o grau de resistência deste o que possibilita dar forma ao vale.

Vale destacar que o rio Poti se apresenta encaixado no Lineamento Transbrasiliano, que se constitui uma falha na crosta terrestre gerada no Período Geológico chamado Neoproterozóico, associado ao Ciclo Orogenético Brasiliano de mesma idade, que ocorreu entre 750 e 540 milhões de anos antes do presente, no período em que o cráton do São Francisco chocou-se com o amazônico, conforme Curto et al. (2015) apud Santos (2018).

No que diz respeito o acesso ao referido local o mesmo é feito por estrada carroçável que leva até 50 metros do local, sendo a acessibilidade e a visibilidade considerada boa (Figura 5).

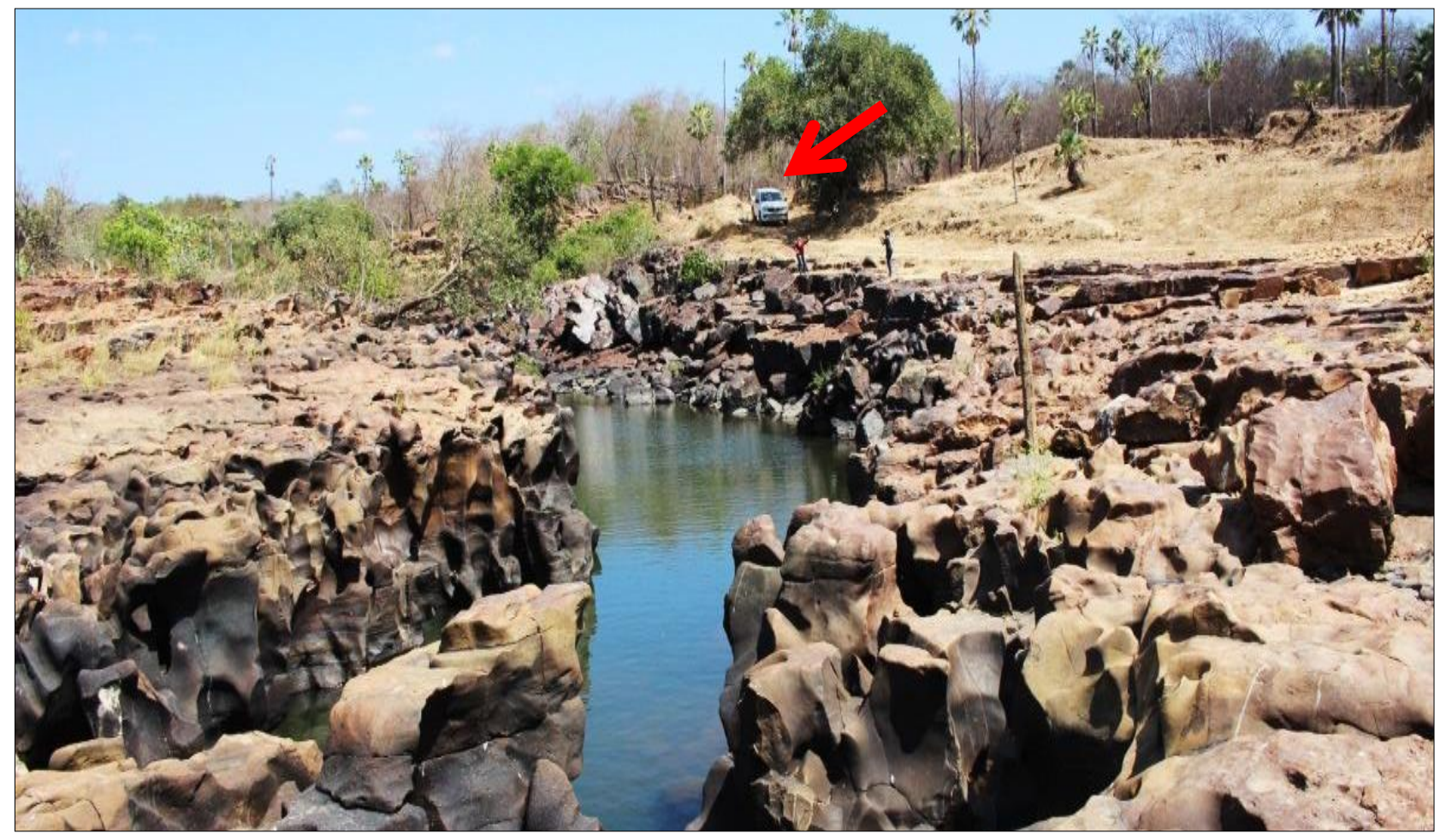

Figura 5: Detalhes do acesso ao geomorfossítio Complexo Mini Cânion do Rio Poti.

Com valores científico, didático, ecológico, turístico, cultural, estético e econômico elevados, os interesses geológico/geomorfológico do local são variados. É possível discutir temáticas como o processo de rupturas (fraturas e juntas) e falhamentos, de como se formam os cânions, além da discussão acerca das formas de transporte de sedimentos (arraste de materiais, rolamento, saltamento) e erosão fluvial, através do processo de corrosão, embate das águas com os sedimentos (areias e seixos), atrito e desgaste das rochas fruto da ação da água (Figura 6). 


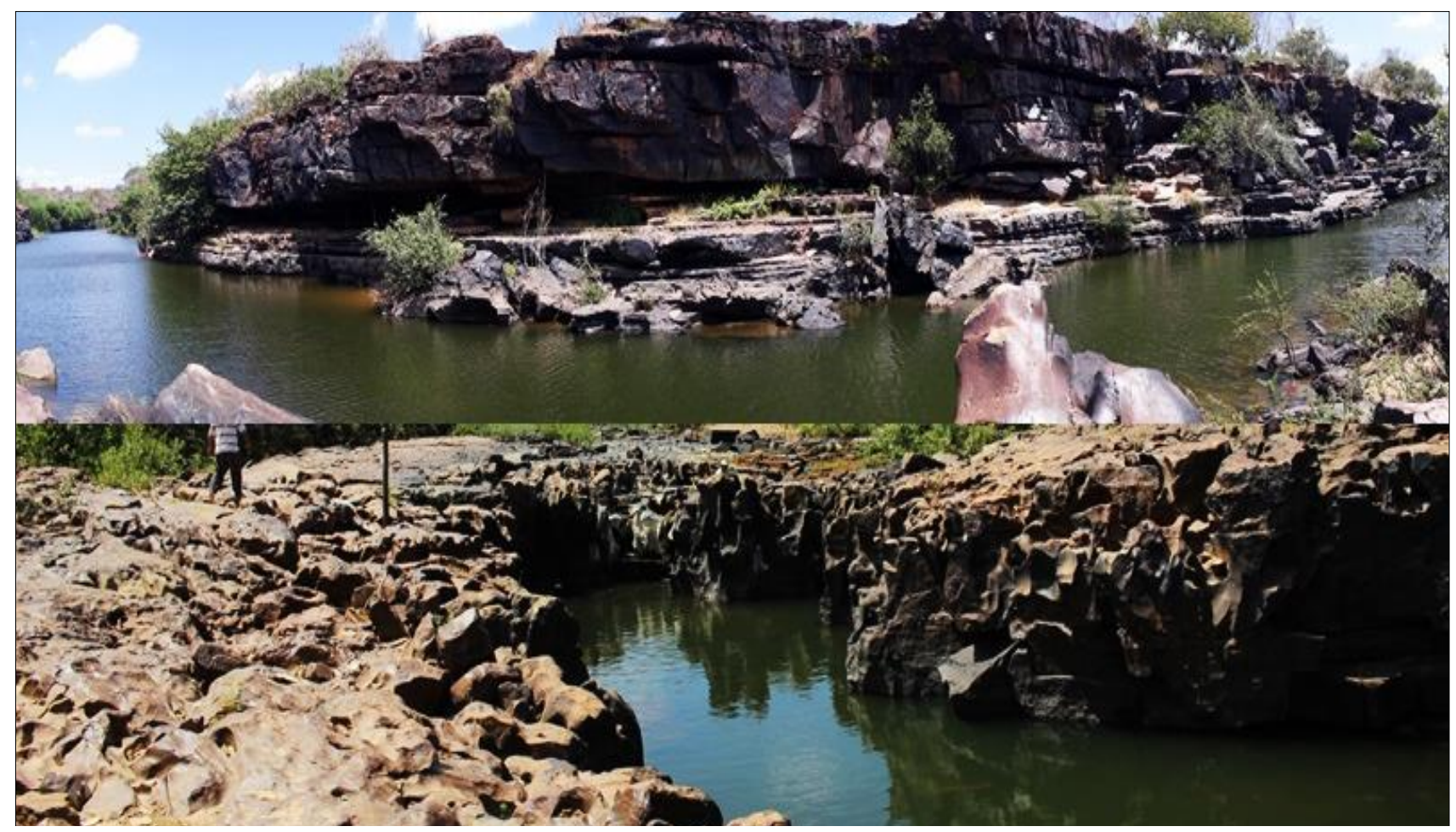

Figura 6: Geomorfossítio Complexo Mini Cânion do Rio Poti.

No local são encontradas cavidades de variados tamanhos e profundidades, fruto de processos erosivos decorrentes da ação da água sobre a rocha, que elaboram cavidades conhecidas como marmitas ou pot holes, resultante da erosão hídrica (Figura 7).
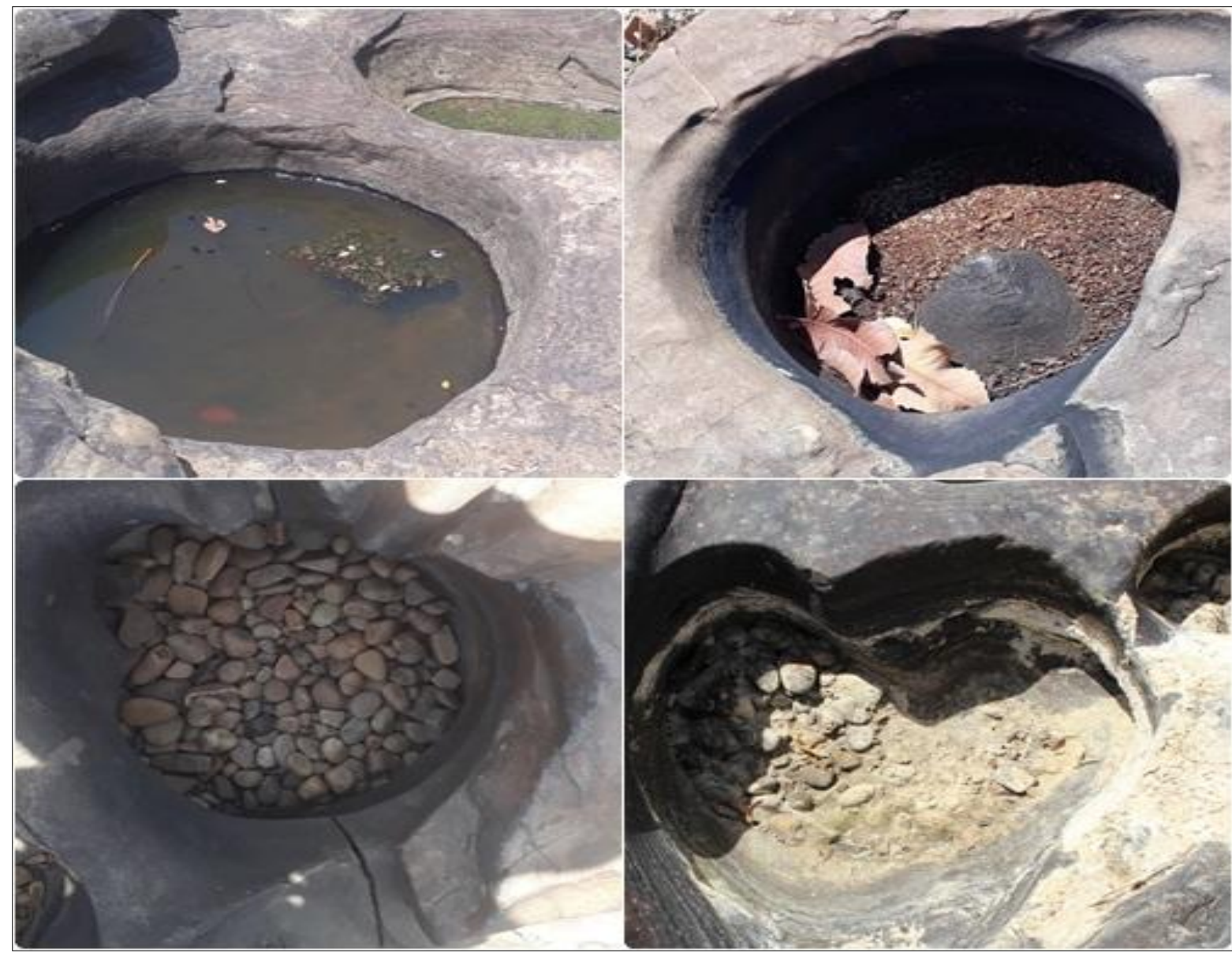

Figura 7: Marmitas ou pot holes, resultante da erosão hídrica no geomorfossítio Complexo Mini Cânion do Rio Poti. 
Além disso, é possível discutir e observar paredões da Formação Cabeças que afloram em diversas áreas do município em questão (Figura 8).

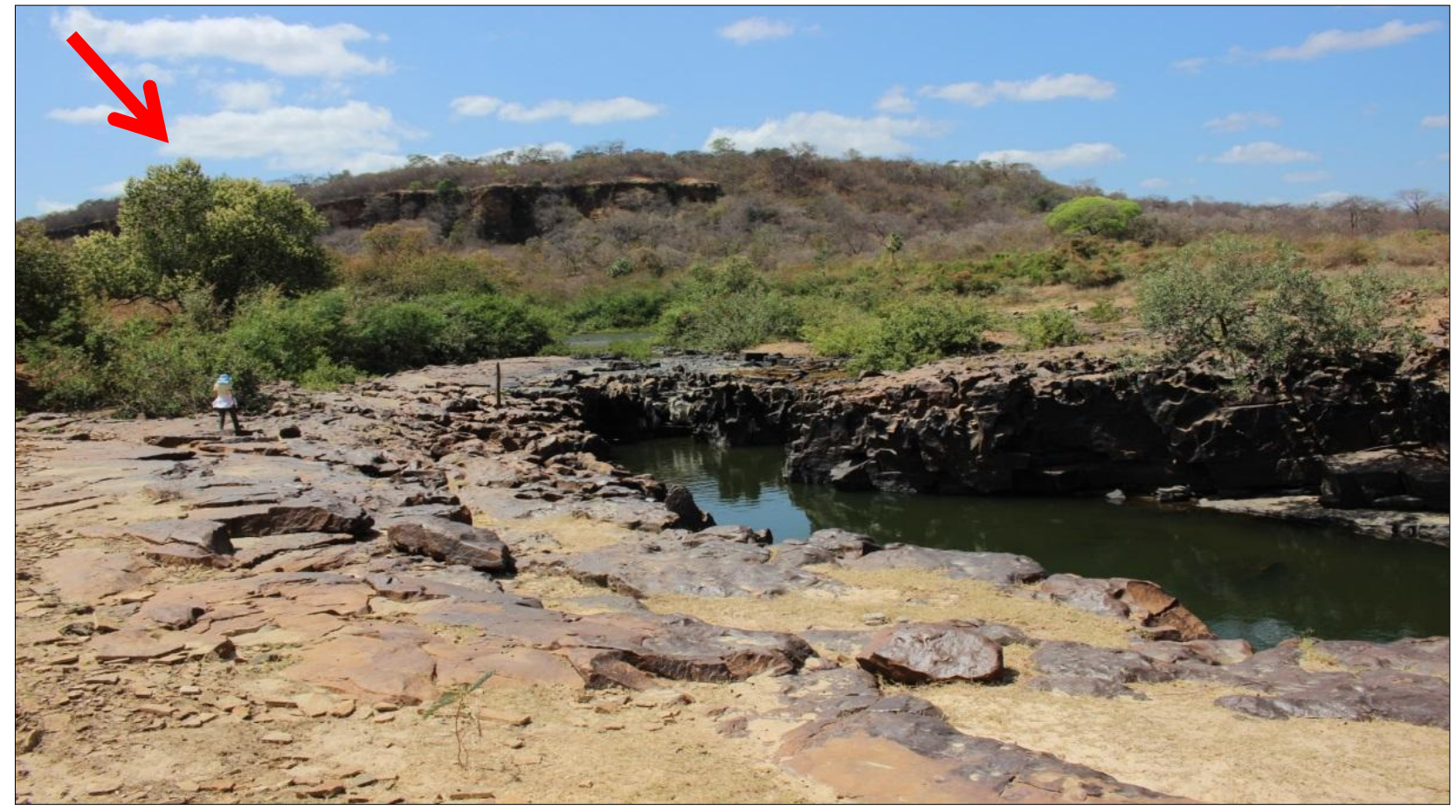

Figura 8: Paredões da Formação Cabeças/Complexo Mini Cânion do Rio Poti.

No local ainda é possível encontrar importante quedas d'agua, como a Cachoeira da Casa de Pedra (Figura 9).

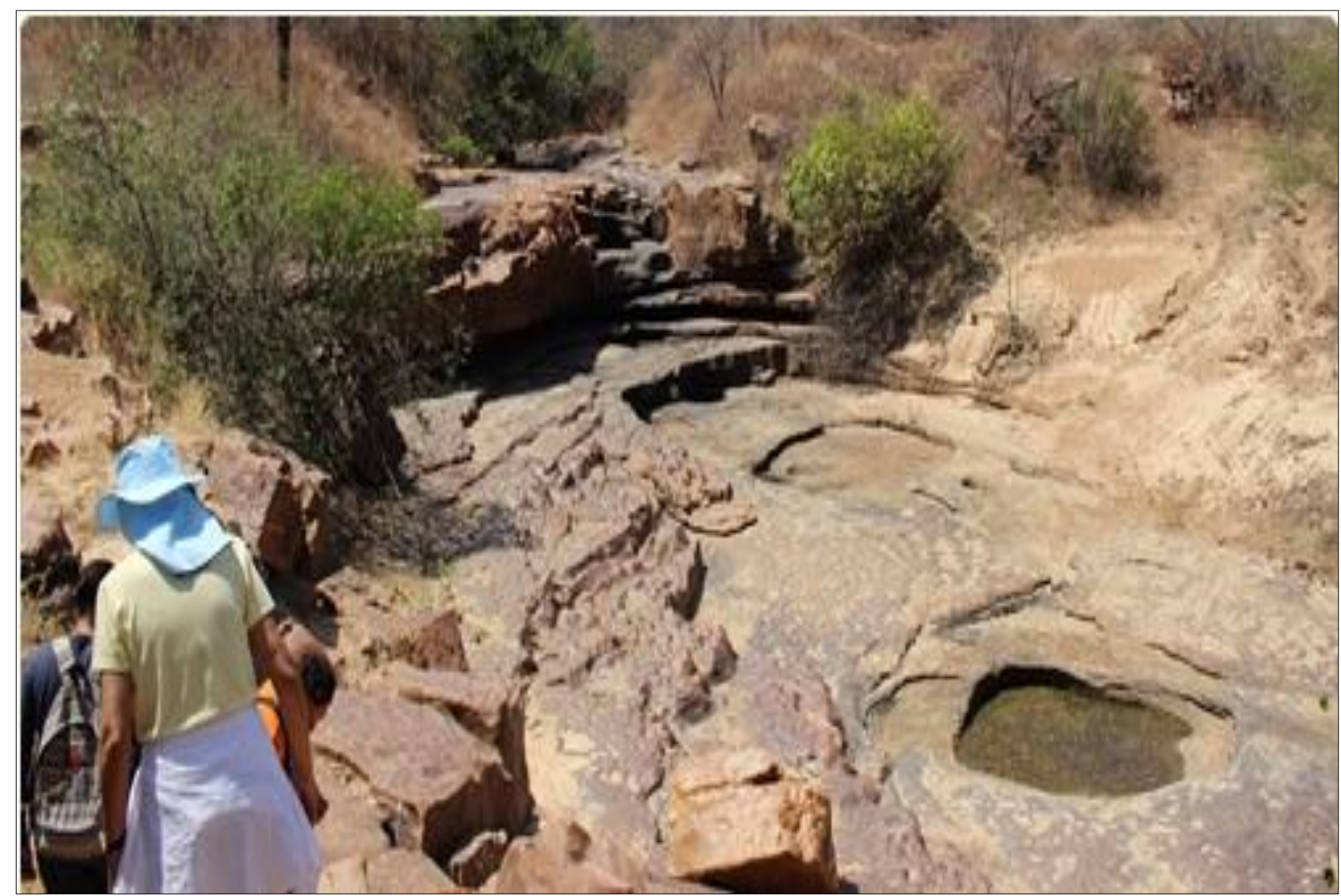

Figura 9: Cachoeira da Casa de Pedra (período de estiagem)/Geomorfossítio Complexo Mini Cânion do Rio Poti. 
Do ponto de vista cultural o local ainda permite a discussão sobre povos primitivos, evidências préhistóricas (arqueológicas), uma vez que existe grande quantidade de gravuras rupestres (imagens em incisões na própria rocha/lajedo), o que agrega valor cultural e histórico a este geomorfossítio (Figura 10).

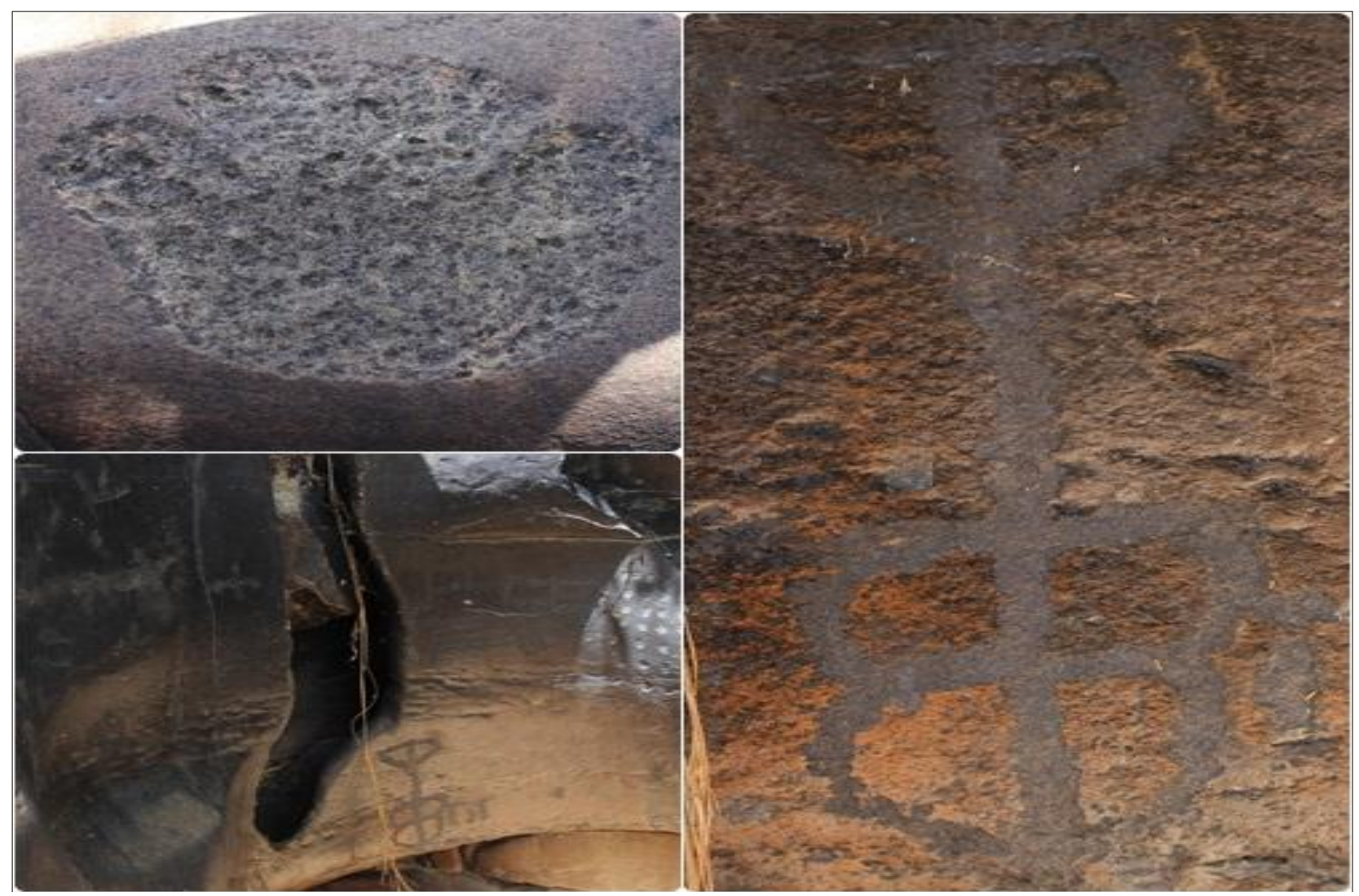

Figura 10: Gravuras rupestres encontradas no geomorfossítio Complexo Mini Cânion do Rio Poti.

Vale ressaltar que o referido geomorfossítio encontra-se em bom estado de conservação, as vulnerabilidades observadas são principalmente de ordem natural. Com proteção insuficiente e sem gestão pelo poder público o local não apresenta deterioração.

Diante do contexto delineado, com base nas informações obtidas no inventário (identificação, caracterização e avaliação qualitativa) foi realizada a avaliação quantitativa do geomorfossítio Complexo Mini Cânion do Rio Poti.

De acordo com a ficha de quantificação adaptada de Pereira (2006) a avaliação quantitativa/numérica leva em consideração os indicadores valor científico (VCi) e valor adicional (VAd) que constituem o valor geomorfológico (VGm) do local e os indicadores valor de uso (VUs) e valor de preservação (VPr) que referem o seu valor de gestão (VGt).

De acordo com Pereira (2006) em termos quantitativos, tanto VGm como VGt têm o mesmo peso, com o máximo de 10 pontos, sendo atribuída pontuação máxima de 5,5 a VCi, de 4,5 a VAd, de 7 a VUs e de 3 a VPr. Como indicador de conjunto, introduz-se o Valor Total (VT), que equivale à soma das pontuações obtidas em todos os critérios.

O Valor Total (VT) de um geomorfossítio equivale à soma do seu valor geomorfológico (VGm) e do seu valor de gestão (VGt), correspondendo à soma das pontuações atribuídas em todos os critérios.

No indicador valor científico (VCi) avaliaram-se os critérios abundância relativa (Ar), integridade (I), representatividade (R), diversidade (D), elementos geológicos (G), conhecimento científico (K) e abundância nacional (An).

No indicador valor adicional (VAd) incluíram-se os critérios valor cultural (Cult), valor estético (Estet) e valor ecológico (Ecol). No indicador valor de uso (VUs), são considerados os critérios acessibilidade (Ac), visibilidade $(\mathrm{V})$, outros usos $(\mathrm{U})$, uso geomorfológico $(\mathrm{Ug})$, proteção $(\mathrm{P})$ e equipamentos $(\mathrm{E})$. E no indicador valor de proteção (VPr) foram considerados os critérios integridade (Ip) e vulnerabilidade (Vu). Os resultados desta avaliação são apresentados na Tabela 1. 
Tabela 1: Quantificação (avaliação numérica/quantitativa) dos geomorfossítio Complexo Mini Cânion do Rio Poti, com os 07 indicadores considerados na metodologia empregada (PEREIRA, 2006).

\begin{tabular}{c|c|c|c|c|c|c|c}
\hline Geomorfossítio & VCi & VAd & VGm & VUs & VPr & VGt & VT (VGm + VGt) \\
\hline $\begin{array}{c}\text { Complexo Mini } \\
\text { Cânion do Rio Poti }\end{array}$ & 4,33 & 3,75 & 8,08 & 5,74 & 0,75 & 6,49 & 14,57 \\
\hline
\end{tabular}

A seguir é apresentado de forma sucinta informações sobre o referido geomorfossítio colocadas na tabela de seriação considerando os indicadores Valor Científico (VCi), Valor Adicional (VAd), Valor Geomorfológico (VGm), Valor de Uso (VUs), Valor de Preservação (VPr), Valor de Gestão (VGt) e ainda o Valor Total (VT).

\section{- Valor Científico (VCi)}

De acordo com a tabela acima no que se refere ao Valor Científico (VCi), o referido geomorfossítio obteve uma boa pontuação, 4,33 pontos (pontuação máxima=6). Esse dado confere ao local alta importância científica, relativamente aos aspectos geológico, geomorfológico e arqueológico em destaque.

- Valor Adicional (VAd)

No indicador VAd, o geomorfossítio Complexo Mini Cânion do Rio Poti obteve 3,75 pontos, onde a pontuação máxima é de 4,5 pontos. A boa pontuação adquirida é explicada pelo fato de o mesmo ter elevado valor estético associado à morfologia, quer pelo controle das geoformas no estabelecimento de valores ecológicos (biodiversidade, por exemplo) ou devido ao elevado valor cultural associado a ambos.

- Valor Geomorfológico (VGm)

No Valor Geomorfológico conta o somatório dos indicadores VCi e VAd, o mesmo colocou o geomorfossítio Complexo Mini Cânion do Rio Poti com pontuação de 8,08 pontos.

- Valor de Uso (Vus)

No indicador VUs, foi atribuída ao geomorfossítio a pontuação de 5,74 pontos, onde a pontuação máxima é de 7,60 pontos. Esta pontuação elevada está relacionada com a atribuição da pontuação máxima nos critérios Condições de visibilidade (V), Uso atual do interesse geomorfológico (Ug), Outros interesses, naturais e culturais, e usos atuais (U) e Equipamentos e serviços de apoio ao uso (E).

- Valor de Preservação (VPr)

Apenas com dois critérios considerados (Integridade e Vulnerabilidade), nesse indicador a pontuação máxima é de 3 pontos para os mais degradados. O geomorfossítio Complexo Mini Cânion do Rio Poti obteve nota baixa, apenas 0,75 pontos o que indica a boa preservação do estado natural da maioria.

- Valor de Gestão (VGt)

No Valor de Gestão conta o somatório dos indicadores VUs que foi 5,74 e VPr que foi 0,75, como citado acima, o mesmo colocou o geomorfossítio Complexo Mini Cânion do Rio Poti com pontuação de 6,49 pontos.

- Valor total (VT)

O geomorfossítio Complexo Mini Cânion do Rio Poti (VT=14,57), devido à boa pontuação nos outros seis indicadores, obteve uma boa nota no Valor Total.

A etapa de quantificação (avaliação quantitativa e seriação) é de fundamental importância para distinguir o geomorfossítio dentro de um contexto, servindo como método de seleção e de comparação de locais no âmbito da gestão do patrimônio geomorfológico. Dessa forma, realizar a avaliação de apenas de um geomorfossítio perde o sentido, uma vez que não há outras referências para efetivar a comparação. Porém, como salientado, o presente trabalho está inserido no âmbito do inventário e avaliação do geopatrimônio dos municípios de Juazeiro do Piauí, Novo Santo Antonio, São João da Serra e Sigefredo Pacheco, Piauí, onde se inventariaram e quantificaram trinta e seis geossítios/geomorfossítios (Tabela 2). 
Tabela 2: Seriação dos geossítios/geomorfossítios dos municípios de Juazeiro do Piauí, Novo Santo Antonio, São João da Serra e Sigefredo Pacheco, Piaú́.

\begin{tabular}{|c|c|c|c|c|c|c|c|}
\hline Posição & $\mathrm{VCi}$ & VAd & VGm & VUs & VPr & VGt & VT \\
\hline $1^{\circ}$ & G22 $(4,33)$ & G26 $(3,87)$ & G22 $(8,08)$ & G25 $(6,24)$ & G14 $(1,75)$ & G25 $(6,74)$ & G22 $(14,57)$ \\
\hline $2^{\circ}$ & G17 $(3,58)$ & G33 $(3,87)$ & G26 $(7,28)$ & G22 $(5,74)$ & G17 $(1,25)$ & G22 $(6,49)$ & G18 $(12,61)$ \\
\hline $3^{\circ}$ & G20 $(3,42)$ & G22 $(3,75)$ & G20 $(7,17)$ & G18 $(5,24)$ & G15 $(1,25)$ & G18 $(6,49)$ & G20 $(12,57)$ \\
\hline $4^{0}$ & G26 $(3,41)$ & G20 $(3,75)$ & G33 $(6,95)$ & G29 $(5,24)$ & G33 $(1,25)$ & G29 $(6,49)$ & G17 $(11,75)$ \\
\hline $5^{\circ}$ & G15 $(3,08)$ & G18 $(3,37)$ & G17 $(6,83)$ & G16 $(5,05)$ & G06 $(1,25)$ & G01 $(6,23)$ & G26 $(11,57)$ \\
\hline $6^{0}$ & G33 $(3,08)$ & G17 $(3,25)$ & G18 $(6,12)$ & G01 $(4,98)$ & G10 $(1,25)$ & G23 $(6,18)$ & G23 $(11,55)$ \\
\hline $7^{\circ}$ & G05 $(3,00)$ & G34 $(3,13)$ & G34 $(5,88)$ & G23 $(4,93)$ & G18 $(1,25)$ & G35 $(6,15)$ & G33 $(11,53)$ \\
\hline $8^{\circ}$ & G06 $(2,75)$ & G27 $(3,13)$ & G06 $(5,75)$ & G20 $(4,9)$ & G23 $(1,25)$ & G16 $(6,05)$ & G35 $(11,52)$ \\
\hline $9^{\circ}$ & G10 $(2,75)$ & G06 $(3,0)$ & G23 $(5,37)$ & G35 $(4,9)$ & G24 $(1,25)$ & G07 $(6,02)$ & G01 $(11,51)$ \\
\hline $10^{\circ}$ & G16 $(2,75)$ & G01 $(2,87)$ & G31 $(5,37)$ & G07 $(4,77)$ & G31 $(1,25)$ & G11 $(5,9)$ & G34 $(11,1)$ \\
\hline $11^{\circ}$ & G18 $(2,75)$ & G23 $(2,62)$ & G35 $(5,37)$ & G11 $(4,65)$ & G34 $(1,25)$ & G32 $(5,9)$ & G07 $(11,05)$ \\
\hline $12^{\circ}$ & G23 $(2,75)$ & G31 $(2,62)$ & G01 $(5,28)$ & G32 $(4,65)$ & G35 $(1,25)$ & G21 $(5,82)$ & G25 $(10,95)$ \\
\hline $13^{\circ}$ & G24 $(2,75)$ & G35 $(2,62)$ & G07 $(5,03)$ & G21 $(4,57)$ & G01 $(1,25)$ & G36 $(5,76)$ & G16 $(10,92)$ \\
\hline $14^{\circ}$ & G31 $(2,75)$ & G07 $(2,62)$ & G08 $(5,03)$ & G19 $(4,57)$ & G07 $(1,25)$ & G04 $(5,66)$ & G08 $(10,9)$ \\
\hline $15^{\circ}$ & G34 $(2,75)$ & G08 $(2,62)$ & G15 & G36 $(4,51)$ & G08 $(1,25)$ & G08 (5 & G31 $(10,85)$ \\
\hline $16^{\circ}$ & G35 $(2,75)$ & G15 $(2,12)$ & G05 (4 & G02 $(4,49)$ & G21 $(1,25)$ & G14 $(5,49)$ & G24 $(10,05)$ \\
\hline $17^{\circ}$ & G25 $(2,58)$ & G16 $(2,12)$ & G16 $(4,87)$ & G04 $(4,41)$ & G09 $(1,25)$ & G31 $(5,48)$ & G15 $(9,91)$ \\
\hline $18^{\circ}$ & G01 $(2,41)$ & G24 $(2,12)$ & G24 $(4,87)$ & G08 $(4,31)$ & G11 $(1,25)$ & G20 $(5,4)$ & G29 $(9,85)$ \\
\hline $19^{\circ}$ & G07 $(2,41)$ & G05 $(1,88)$ & G27 $(4,71)$ & G05 $(4,3)$ & G13 $(1,25)$ & G19 $(5,32)$ & G10 $(9,59)$ \\
\hline $20^{\circ}$ & G08 $(2,41)$ & G25 $(1,63)$ & G10 $(4,37)$ & G31 $(4,23)$ & G28 $(1,25)$ & G09 $(5,32)$ & G06 $(9,53)$ \\
\hline $21^{\circ}$ & G02 $(2,25)$ & G10 $(1,62)$ & $\mathrm{G} 25$ & G09 $(4,07)$ & 25) & G1 & G05 $(9,18)$ \\
\hline $22^{\circ}$ & G21 $(2,08)$ & G29 $(1,62)$ & G29 & G10 $(3,97)$ & $25)$ & G34 & G27 $(8,82)$ \\
\hline $23^{\circ}$ & G09 $(1,75)$ & G30 $(1,62)$ & G30 $(3,36)$ & G34 $(3,97)$ & G32 $(1,25)$ & G24 $(5,18)$ & G21 $(8,78)$ \\
\hline $24^{\circ}$ & G11 $(1,74)$ & G12 $(1,13)$ & G02 $(3,13)$ & G24 $(3,93)$ & G36 $(1,25)$ & $\operatorname{G13}(5,11)$ & G11 $(8,52)$ \\
\hline $25^{\circ}$ & G13 $(1,74)$ & G02 $(0,88)$ & G21 $(2,96)$ & G13 $(3,86)$ & G04 $(1,25)$ & G30 $(5,0)$ & G32 $(8,52)$ \\
\hline $26^{\circ}$ & G28 $(1,74)$ & G21 $(0,88)$ & G11 $(2,62)$ & G30 $(3,75)$ & G03 $(1,25)$ & G12 $(4,99)$ & G36 $(8,38)$ \\
\hline $27^{\circ}$ & G29 $(1,74)$ & G11 $(0,88)$ & G13 $(2,62)$ & G14 $(3,74)$ & G12 $(1,25)$ & G17 $(4,92)$ & G30 $(8,36)$ \\
\hline $28^{\circ}$ & G30 $(1,74)$ & G13 $(0,88)$ & G28 (2 & G12 $(3,74)$ & G16 $(1,00)$ & G15 $(4,89)$ & G02 $(7,87)$ \\
\hline $29^{\circ}$ & G32 $(1,74)$ & G28 ( & G32 (2 & G17 $(3,67)$ & G22 $(0,75)$ & G02 $(4,74)$ & G04 $(7,83)$ \\
\hline $30^{\circ}$ & G36 $(1,74)$ & G32 $(0,88)$ & G36 $(2,62)$ & G15 $(3,64)$ & G26 $(0,75)$ & G28 $(4,66)$ & G19 $(7,78)$ \\
\hline $31^{\circ}$ & G19 $(1,58)$ & G36 $(0,88)$ & G19 $(2,46)$ & G26 $(3,54)$ & G19 $(0,75)$ & G33 $(4,58)$ & G13 $(7,73)$ \\
\hline $32^{\circ}$ & G27 $(1,58)$ & G19 $(0,88)$ & G03 $(2,29)$ & G28 $(3,41)$ & G27 $(0,75)$ & G05 $(4,3)$ & G14 $(7,62)$ \\
\hline $33^{\circ}$ & G04 $(1,42)$ & G03 $(0,88)$ & G09 $(2,25)$ & G27 $(3,36)$ & G20 $(0,50)$ & G26 $(4,29)$ & G09 $(7,57)$ \\
\hline $34^{\circ}$ & G03 $(1,41)$ & G14 $(0,88)$ & G12 $(2,21)$ & G33 $(3,33)$ & G25 $(0,50)$ & G27 $(4,11)$ & G28 $(7,28)$ \\
\hline $35^{\circ}$ & G14 $(1,25)$ & G04 $(0,75)$ & G04 $(2,17)$ & G06 $(2,53)$ & G02 $(0,25)$ & G06 $(3,78)$ & G12 $(7,2)$ \\
\hline $36^{\circ}$ & G12 $(1,08)$ & G09 $(0,5)$ & G14 $(2,13)$ & G03 $(1,52)$ & G05 $(0,0)$ & G03 $(2,77)$ & G03 $(5,06)$ \\
\hline
\end{tabular}

Nesse contexto, é apresentada em destaque na Tabela 2 as posições do geomorfossítio Complexo Mini Cânion do Rio Poti (G22) no que tange os indicadores (Valor Científico (VCi), Valor Adicional (VAd), Valor Geomorfológico (VGm), Valor de Uso (VUs), Valor de Preservação (VPr), Valor de Gestão (VGt) e ainda o Valor Total (VT) no contexto da área em análise.

É possível visualizar que o geomorfossítio Complexo Mini Cânion do Rio Poti (G22) se destacou como o de maior valor científico, juntamente com o geomorfossítio Cachoeira da Roça Velha (G17) localizado no município de Novo Santo Antônio, Piauí (Tabela 2). Também é possível observar seu alto valor do ponto de vista geomorfológico, onde o mesmo ficou na primeira posição diante dos trinta e seis geossítios/geomorfossítios.

Apenas no indicador Valor de Proteção (VPr) quando observada a comparação, o geomorfossítio Complexo Mini Cânion do Rio Poti não aparece em boas colocações, sendo o vigésimo nono $\left(29^{\circ}\right)$ o que indica a boa preservação do estado natural.

Salienta-se assim que o geomorfossítio Complexo Mini Cânion do Rio Poti apresenta relevância em todos os indicadores, sendo então um local propício para a realização atividades de educação ambiental, no desenvolvimento turístico e no enriquecimento do conhecimento sobre as características geológicas, geomorfológicas e arqueológicas. 


\subsection{Valorização e divulgação do Geomorfossítio Complexo Mini Cânion do Rio Poti}

As etapas de valorização e divulgação do patrimônio geomorfológico são, no contexto das estratégias de geoconservação, os momentos de maior proximidade entre os pesquisadores, os órgãos gestores e o público. É nessa fase que os dados obtidos são adaptados à uma linguagem passível de entendimento fora do meio acadêmico, configurando ações aplicadas à gestão e à conservação ambiental (MEIRA, 2016).

Precedendo a etapa de divulgação do patrimônio geomorfológico, as medidas de valorização são responsáveis pela construção de um aparato técnico e do planejamento necessário para suportar o aumento na visitação e a melhoria das experiências dos visitantes. Compreendem assim o conjunto de ações relacionadas à informação e à interpretação dos geossítios/geomorfossítios, possibilitando que os visitantes reconheçam os seus valores.

Quanto à divulgação Brilha (2005) aponta que pode ser efetuada por intermédio de ações específicas ou em conjugação com outras ações. Nesse contexto, foram construídas propostas de valorização e divulgação para o geomorfossítio Complexo Mini Cânion do Rio Poti, tendo como ponto de partida as suas potencialidades científicas, educativas, turísticas e culturais.

As propostas buscam o aproveitamento da história, geologia e cultura, para construir uma narrativa em prol da conservação ambiental e popularização do conhecimento geológico, geomorfológico e arqueológico.

Como estratégias de valorização do geomorfossítio Complexo Mini Cânion do Rio Poti foi proposta a confecção de um painel interpretativo que aborda o seu potencial do ponto de vista geológico, geomorfológico e arqueológico (Figura 11).

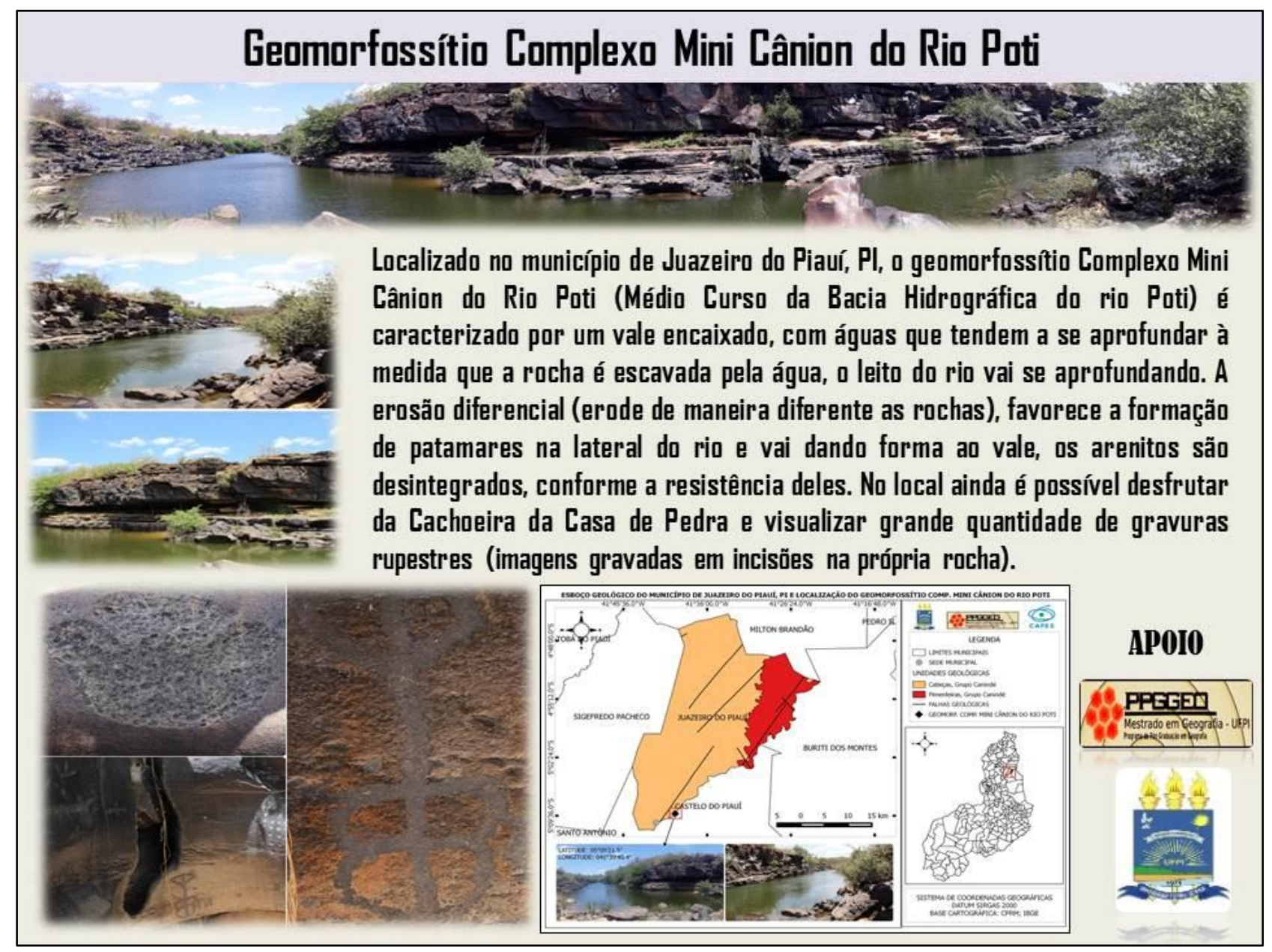

Figura 11: Detalhes da proposta de confecção de um painel interpretativo para o geomorfossítio Complexo Mini Cânion do Rio Poti, Juazeiro do Piauí, PI.

Quanto ao formato dos painéis sugere-se formato paisagem, tamanho de $120 \mathrm{~cm}$ de largura por $90 \mathrm{~cm}$ de altura, podendo ser disposto tanto lateral (mesa) como verticalmente, com base fixada a uma altura que permita a leitura por crianças e cadeirantes, confeccionados com materiais com preço acessível, podendo ser 
rochas da região (podendo ser utilizados blocos rochosos soltos da área ou rochas extraídas), em ferro galvanizado, ou em madeira, devidamente envernizada a fim que resista por mais tempo aos processos intempéricos (PEREIRA, 2006; SILVA, 2017).

Ainda foi proposta a confecção de souvenires, pois servem para valorizar e divulgar este patrimônio, produtos procurados pelos turistas para presentear alguém que não esteve presente na viajem ou para relembrar o local visitado (MOESH, 2000).

Contribuindo significativamente para o desenvolvimento sustentável local, valorização da geodiversidade e o saber fazer da comunidade, Degrandi et al. (2018) enfatiza que a criação de produtos (artesanato) representa a identidade cultural e natural do local e ainda reverte-se em fonte de renda para os habitantes locais.

Diante desse contexto, aliando as peculiaridades do geomorfossítio avaliado apresenta-se a seguir sugestões de souvenires (Figura 12).

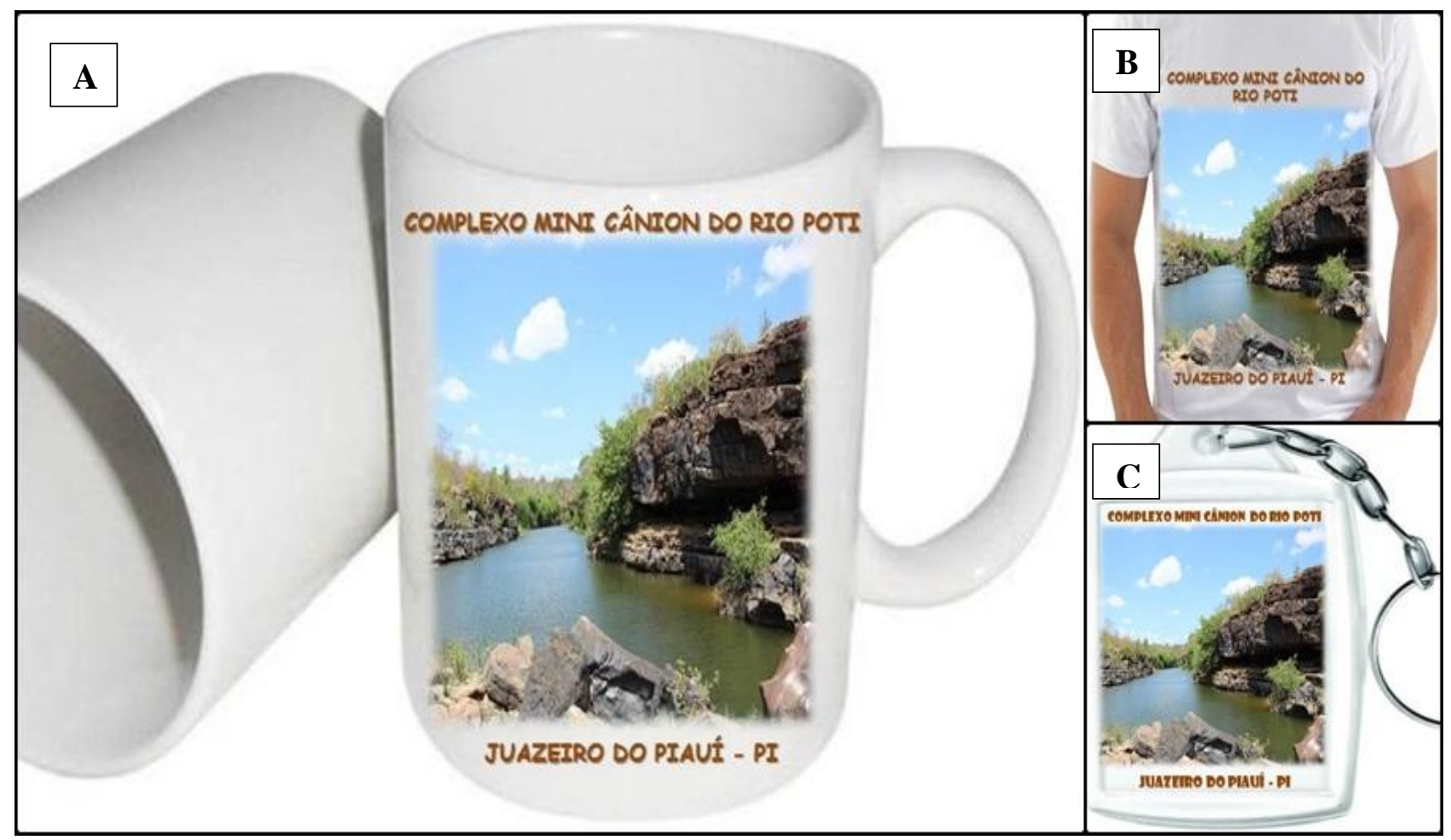

Figura 12: Sugestões de souvenires para o geomorfossítio Complexo Mini Cânion do Rio Poti. ACanecas; B- Camisas; C - Chaveiros.

\section{Conclusões}

De maneira geral, constatou-se que o geomorfossítio Complexo Mini Cânion do Rio Poti localizado no municipio de Juazeiro do Piauí, Piauí, apresenta valores científico, didático, ecológico, turístico, cultural, estético e econômico elevado. O referido geomorfossítio, tem grande potencial, sobretudo, no viés geoturístico com a exploração didático-científica e cultural.

De caráter cênico excepcional suas geoformas e a singularidade visual dos elementos geomorfológicos aliado a aspectos culturais físicos e imateriais de elevado valor possibilitam explicar parte da história geológica/evolutiva do Estado, por meio do entendimento da origem e constante modificação do relevo da área.

Através da avaliação foi possível confirmar que o local se destaca em todos os indicadores: Valor Científico (VCi), Valor Adicional (VAd), Valor Geomorfológico (VGm), Valor de Uso (VUs), Valor de Preservação (VPr), Valor de Gestão (VGt) e ainda o Valor Total (VT). Os valores científico e geomorfológico são os mais salientados, especialmente em função da diversidade de elementos da geodiversidade. 
As pontuações alcançadas na avaliação demonstram que o geomorfossítio pode ser amplamente utilizado em atividades científicas, educativas e turísticas, tanto pelas suas aptidões como pelo baixo risco de degradação da área.

Já as propostas de valorização e divulgação expõe o caráter aplicado do estudo. Por meio das estratégias, que integram preceitos da geocomunicação, interpretação e educação ambiental as ações apresentadas: confecção de um painel interpretativo e confecção de souvenires são de suma importância.

Vale ressaltar assim a necessidade de um plano de aproveitamento deste geomorfossítio como forma de fortalecer o turismo na região, e com isso dinamizar a economia do município. Os gestores precisam conscientizar-se de que a geodiversidade da região, constituem-se elemento-chave para a promoção do desenvolvimento socioeconômico das comunidades locais de forma sustentável.

\section{Referências}

AGUIAR, Robério Bôto de.; GOMES, José Roberto de Carvalho. Projeto cadastro de fontes de abastecimento por água subterrânea, estado do Piauí: diagnóstico do município de Juazeiro do Piauí. Fortaleza: CPRM, 2004.

BAPTISTA, Elisabeth Mary de Carvalho; LIMA, Iracilde Maria de Moura Fé; MOURA, Liége de Souza; SILVA, Brenda Rafaele Viana da. Panorama dos estudos sobre geoconservação no estado do Piauí no período de 2010 a 2018. Carta CEPRO, Teresina, v.30, n.1, p.39-58, jan./jun. 2018.

BRILHA, J. Patrimônio geológico e geoconservação: a conservação da natureza na sua vertente geológica. Braga: Palimage, 2005.

BRILHA, J., CARVALHO, A. Geoconservação em Portugal - Uma Introdução in Geologia e Património Natural (Geodiversidade). Assoc. Port. Geólogos, Soc. Port. De Geologia. Vol. II, Cap. IV, 2010, p. 435441.

CARCAVILLA, U. L., LÓPEZ-MARTÍNEZ, J. Y.; DURÁN, J. J. Patrimonio geológico y geodiversidad: investigación, conservación, gestión y relación con los espacios naturales protegidos. Cuadernos del Museo Geominero, n.7. Madrid: Instituto Geológico y Minero de Espanã, 2007.

FERREIRA, Rogério Valença; DANTAS, Marcelo Eduardo. Relevo. In: PFALTZGRAFF, Pedro Augusto dos Santos; TORRES, Fernanda Soares de Miranda; BRANDÃO, Ricardo de Lima (Org.). Geodiversidade do estado do Piauí. Recife: CPRM, 2010, p. 47-64.

GRAY, M. Geodiversity: Valuing and Conserving Abiotic Nature. England: John Wiley \& Sons, Chichester, 2004.

LIMA, Iracilde de Moura Fé. O Relevo Piauiense: Uma proposta de Classificação. In: Carta CEPRO, Teresina, v.12, n.2, 1987, p. 55-84.

LIMA, Enjolras de A. M.; BRANDÃO, Ricardo de Lima. Geologia. In: PFALTZGRAFF, Pedro Augusto dos Santos; TORRES, Fernanda Soares de Miranda; BRANDÃO, Ricardo de Lima (Org.). Geodiversidade do estado do Piauí. Recife: CPRM, 2010, p. 17-24.

LIMA F. F. Proposta Metodológica para a Inventariação do Patrimônio Geológico Brasileiro. Braga, 2008. Dissertação (Mestrado em Patrimônio Geológico e Geoconservação). Universidade do Minho, Portugal, 2008.

LORENCI, C. T. B. Geoturismo: uma ferramenta auxiliar na interpretação e preservação do patrimônio geopaleontológico da região central do Rio Grande do Sul. Santa Maria, 2013. Dissertação (Mestrado em Patrimônio Cultural). Universidade Federal de Santa Maria, Santa Maria, 2013.

MANSUR, Kátia Leite. Patrimônio geológico, geoturismo e geoconservação: uma abordagem da geodiversidade pela vertente geológica. In: GUERRA, Antonio José Teixeira; JORGE, Maria do Carmo Oliveira (Org.). Geoturismo, geodiversidade, geoconservação: abordagens geográficas e geológicas. São Paulo: Oficina de Textos, 2018. p. 01-42. 
MEIRA, Suedio Alves. "Pedras que cantam": o patrimônio geológico do parque nacional de Jericoacoara, Ceará, Brasil. 2016. Dissertação (Mestrado em Geografia). Universidade Estadual do Ceará, Fortaleza, 2016.

MEIRA, Suedio Alves; MORAIS, Jader Onofre de. Os conceitos de geodiversidade, patrimônio geológico e geoconservação: abordagens sobre o papel da geografia no estudo da temática. Boletim geográfico, Maringá, v. 34, n. 3, p. 129-147, 2016.

MOESCH, M. M. A produção do saber turístico. Contexto, São Paulo, 2000.

NASCIMENTO , Marcos Antonio Leite do; MANSUR, Kátia Leite; e MOREIRA, Jasmine Cardozo. Bases conceituais para entender geodiversidade, patrimônio geológico, geoconservação e geoturismo. Revista Equador. Teresina, Vol.04, No 03, p. 48-69, ago. 2015.

NASCIMENTO, M. A. L., RUCHKYS, U. A.; MANTESSO-NETO, V. Geodiversidade, Geoconservação e Geoturismo: trinômio importante para conservação do patrimônio geológico. Sociedade Brasileira de Geologia-SBE, 2008.

OLIVEIRA, P. C. A. Avaliação do patrimônio geomorfológico potencial dos municípios de Coromandel e Vazante, MG. Uberlândia, 2015. Tese (Doutorado em Ciências Humanas) - Universidade Federal de Uberlândia, Minas Gerais, 2015.

PEREIRA, P. J. S. Patrimônio geomorfológico: conceptualização, avaliação e divulgação - aplicação ao Parque Nacional de Montesinho. Braga, 2006. Tese (Doutorado em Ciências - Geologia). Universidade do Minho, Braga, 2006.

PEREIRA, R.G.F. de A. Geoconservação e desenvolvimento sustentável na Chapada Diamantina (Bahia-Brasil). 2010. Tese (Doutorado em Ciências) - Geologia. Universidade do Minho. Portugal, 2010.

PEREIRA R. F.; BRILHA J.; MARTINEZ J. E. Proposta de enquadramento da geoconservação na legislação ambiental brasileira. Memórias e Notícias, 2008, v. 3, p. 491-494.

RUCHKYS, U. A. Patrimônio Geológico e Geoconservação no Quadrilátero Ferrífero, Minas Gerais: potencial para a criação de um geoparque da UNESCO. Belo Horizonte, 2007. Tese (Doutorado em Geologia). Universidade Federal de Minas Gerais, Belo Horizonte, 2007.

SANTOS, Francílio Amorim dos. Geomorfologia e geodiversidade do médio curso da bacia hidrográfica do rio Poti (Piauí), Nordeste do Brasil. Geosaberes, Fortaleza, v. 8, n. 16, p. 121-131, set./dez. 2018.

SHARPLES, C. Concepts and Principles of Geoconservation. Tasmanian Parks and Wildlife Service. Hobart, 2002.

SILVA, José Francisco de Araújo. Geodiversidade e patrimônio geológico/geomorfológico das "Cidades de Pedras" - Piauí: potencial turístico e didático. 249 f. Dissertação (Mestrado em Geografia) Universidade Federal do Piauí, 2017.

SILVA, H. V. M.; AQUINO, C. M. S. Geodiversidade do município de Juazeiro do Piauí (PI): Potencialidades, vulnerabilidades e ameaças. In: XVIII SBGFA: GEOGRAFIA FÍSICA E AS MUDANÇAS GLOBAIS. Fortaleza, Ceará. Anais... UFCE, Fortaleza, v. 1, 2019.

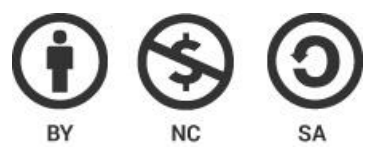

